Table 2. Observed Cannabinoid Concentration of 84 Tested Extract Products Sold Online

\begin{tabular}{lll}
\hline & \multicolumn{2}{l}{$\begin{array}{l}\text { Average Observed Concentration } \\
\text { Across Tests, mg/mL }\end{array}$} \\
\cline { 2 - 3 } Cannabinoid & Mean (SD) & Median (Range) \\
\hline Cannabidiol $^{\mathrm{a}}$ & $30.96(80.86)$ & $9.45(0.10-655.27)$ \\
\hline Cannabidiolic acid $^{2}$ & $1.35(6.74)$ & $0(0-55.73)$ \\
\hline Cannabigerol & $0.08(0.55)$ & $0(0-4.67)$ \\
\hline Cannabinol & 0 & 0 \\
\hline$\Delta-9$-Tetrahydrocannabinol & $0.45(1.18)$ & $0(0-6.43)$ \\
\hline$\Delta-9$-Tetrahydrocannabibolic acid & 0 & 0 \\
\hline
\end{tabular}

a The mean labeled concentration for cannabidiol was $36.86 \mathrm{mg} / \mathrm{mL}$ (SD, 96.56) and the median was $15.00 \mathrm{mg} / \mathrm{mL}$ (range, 1.33-800.0).

14.01\%-31.35\%]), cannabidiolic acid (up to $55.73 \mathrm{mg} / \mathrm{mL}$ ) in 13 of the 84 samples tested (15.48\% [95\% CI, 9.28\%-24.70\%]), and cannabigerol (up to $4.67 \mathrm{mg} / \mathrm{mL}$ ) in 2 of the 84 samples tested (2.38\% [95\% CI, 0.65\%-8.27\%]).

Discussion | Among CBD products purchased online, a wide range of CBD concentrations was found, consistent with the lack of an accepted dose. Of tested products, $26 \%$ contained less CBD than labeled, which could negate any potential clinical response. The overlabeling of CBD products in this study is similar in magnitude to levels that triggered warning letters to 14 businesses in 2015-2016 from the US Food and Drug Administration $^{3}$ (eg, actual CBD content was negligible or less than $1 \%$ of the labeled content), suggesting that there is a continued need for federal and state regulatory agencies to take steps to ensure label accuracy of these consumer products. Underlabeling is less concerning as CBD appears to neither have abuse liability nor serious adverse consequences at high doses ${ }^{4,5}$; however, the THC content observed may be sufficient to produce intoxication or impairment, especially among children. ${ }^{6}$ Although the exclusive procurement of products online is a study limitation given the frequently changing online marketplace, these products represent the most readily available to US consumers. Additional monitoring should be conducted to determine changes in this marketplace over time and to compare internet products with those sold in dispensaries. These findings highlight the need for manufacturing and testing standards, and oversight of medicinal cannabis products.

Marcel O. Bonn-Miller, PhD

Mallory J. E. Loflin, PhD

Brian F. Thomas, PhD

Jahan P. Marcu, PhD

Travis Hyke, MS

Ryan Vandrey, PhD

Author Affiliations: University of Pennsylvania Perelman School of Medicine, Philadelphia (Bonn-Miller); Veterans Affairs San Diego Health Care System, San Diego, California (Loflin); RTI International, Research Triangle Park, North Carolina (Thomas); Americans for Safe Access, Washington DC (Marcu); Palo Alto University, Palo Alto, California (Hyke); Johns Hopkins University School of Medicine, Baltimore, Maryland (Vandrey).

Accepted for Publication: August 7, 2017.
Corresponding Author: Marcel O. Bonn-Miller, PhD, University of Pennsylvania Perelman School of Medicine, 3440 Market St, Ste 370, Philadelphia, PA 19104 (mbonn@pennmedicine.upenn.edu).

Author Contributions: Dr Bonn-Miller had full access to all of the data in the study and takes responsibility for the integrity of the data and the accuracy of the data analysis.

Concept and design: Bonn-Miller, Loflin, Thomas, Vandrey. Acquisition, analysis, or interpretation of data: All authors.

Drafting of the manuscript: Bonn-Miller, Loflin, Marcu, Vandrey.

Critical revision of the manuscript for important intellectual content: Bonn-Miller, Loflin, Thomas, Hyke, Vandrey.

Statistical analysis: Loflin, Marcu.

Obtained funding: Bonn-Miller.

Administrative, technical, or material support: Bonn-Miller, Loflin, Thomas, Hyke, Vandrey.

Supervision: Bonn-Miller.

Conflict of Interest Disclosures: All authors have completed and submitted the ICMJE Form for Disclosure of Potential Conflicts of Interest. Drs Bonn-Miller, Thomas, and Vandrey reported serving as unpaid board members of the Institute for Research on Cannabinoids. Dr Bonn-Miller reported receiving personal fees from Zynerba Pharmaceuticals, the Lambert Center for the Study of Medicinal Cannabis and Hemp, the Realm of Caring Foundation, Tilray, CW Botanicals, Insys Therapeutics, International Cannabis and Cannabinoids Institute, the Medical Cannabis Institute, and Aphria. Dr Vandrey reported receiving personal fees from Zynerba Pharmaceuticals, CW Hemp, Battelle Memorial Institute, and Insys Pharmaceuticals. No other disclosures were reported.

1. Whiting PF, Wolff RF, Deshpande S, et al. Cannabinoids for medical use: a systematic review and meta-analysis. JAMA. 2015;313(24):2456-2473.

2. Vandrey R, Raber JC, Raber ME, Douglass B, Miller C, Bonn-Miller MO. Cannabinoid dose and label accuracy in edible medical cannabis products. JAMA. 2015;313(24):2491-2493

3. US Food and Drug Administration. 2016 Warning letters and test results for cannabidiol-related products. https://www.fda.gov/newsevents /publichealthfocus/ucm484109.htm. Accessed August 15, 2017.

4. Babalonis S, Haney M, Malcolm RJ, et al. Oral cannabidiol does not produce a signal for abuse liability in frequent marijuana smokers. Drug Alcohol Depend. 2017;172:9-13.

5. Bergamaschi MM, Queiroz RH, Zuardi AW, Crippa JA. Safety and side effects of cannabidiol, a Cannabis sativa constituent. Curr Drug Saf. 2011;6(4):237-249.

6. Crippa JA, Crippa AC, Hallak JE, Martín-Santos R, Zuardi AW. $\triangle 9-T H C$ intoxication by cannabidiol-enriched cannabis extract in two children with refractory epilepsy. Front Pharmacol. 2016;7:359.

\section{Association of Trial Registration With Reporting of Primary Outcomes in Protocols and Publications}

A major aim of trial registration is to help identify and deter the selective reporting of outcomes based on the results. ${ }^{1,2}$ However, it is unclear whether registered outcomes accurately reflect the trial protocol and whether registration improves the reporting of primary outcomes in publications. We evaluated adherence to trial registration and its association with subsequent publication and reporting of primary outcomes.

Methods | We conducted a cohort study of all initiated clinical trial protocols approved in 2007 by the research ethics committee for the region of Helsinki and Uusimaa, Finland. Registry records and articles published up to February 2017 were identified using keywords to search trial registries, PubMed, EMBASE, Cochrane Central, Finnish databases (Medic, ARTO, TUHAT), and Google. Trial characteristics and outcomes were extracted in duplicate from each protocol (including amendments), registry record, and publication.

Using descriptive statistics and multivariable logistic regression adjusting for characteristics in Table 1, we determined 


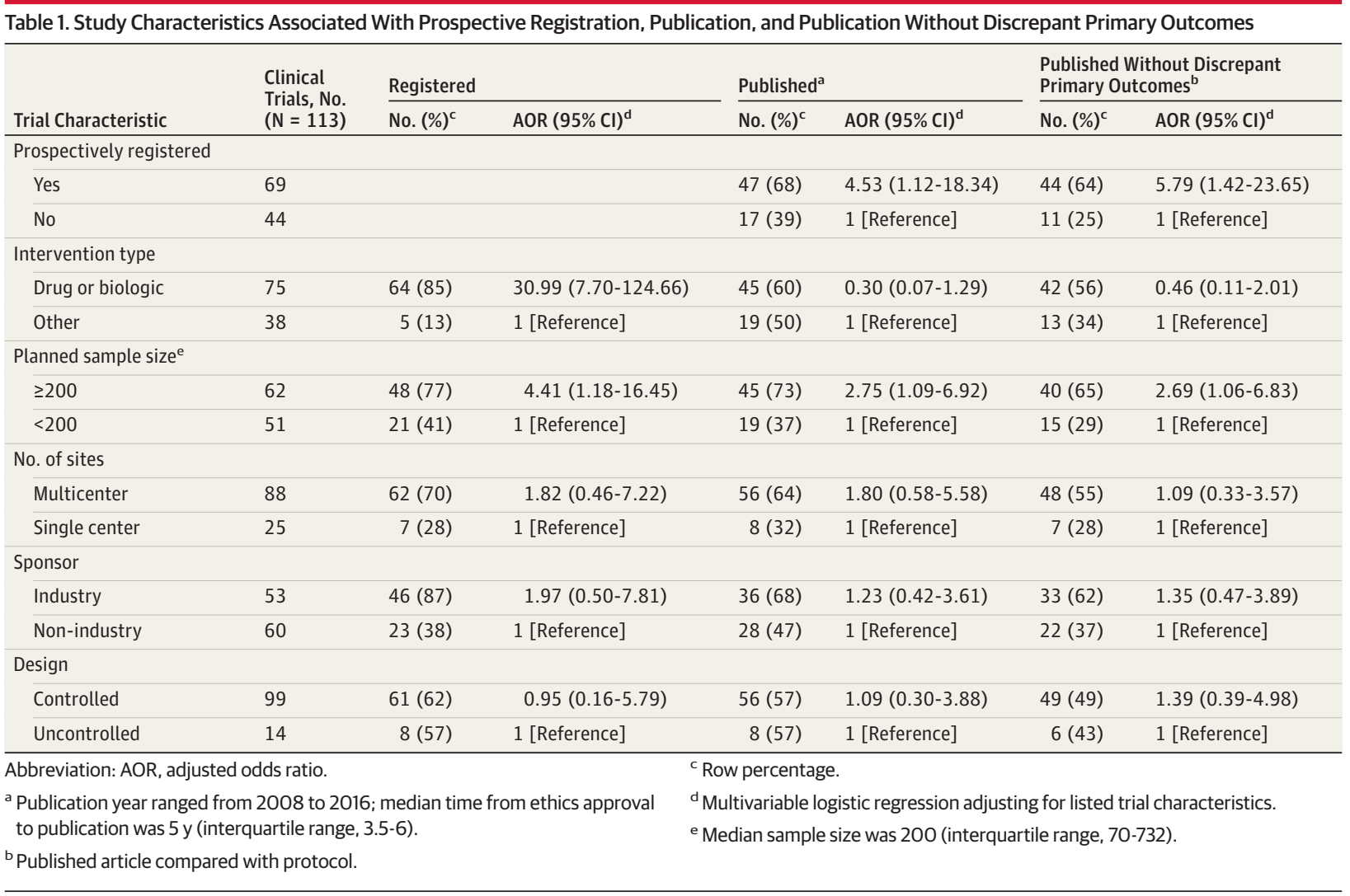

the prevalence of and variables associated with prospective registration (within 1 month after the trial start date to allow for incomplete start dates and processing delays in the registry); the proportion of trials with at least 1 discrepant primary outcome in the protocol compared with (1) the registry and (2) the publication; and the association between prospective registration and subsequent publication without discrepant primary outcomes compared with the protocol. A 2-sided $P$ value of less than .05 was used for statistical significance, and odds ratios (ORs) with 95\% CIs were calculated using Stata/SE (StataCorp), version 12.1.

Discrepancies were defined as (1) a new primary outcome being reported that was not specified as primary in the protocol; or (2) a protocol-defined primary outcome being omitted or downgraded (reported as secondary or unspecified) in the registry or publication. For comparison with registries, we used the primary outcomes defined in the most recent protocol or amendment dated before the initial registration date. For comparison with publications, we used the most recent protocol version regardless of amendment date.

Results | Among 113 trials, 69 (61\%) were prospectively registered and 64 (57\%) were published. Trials involving drug or biologic interventions and larger sample sizes were more likely to be registered (Table 1).

A primary outcome was not defined in 23 protocols (20\%). Discrepancies were found in at least 1 primary outcome defined in the registry for 16 of 69 prospectively registered trials (23\%) when compared with the protocol, whereas
9 of 58 published trials (16\%) with defined primary outcomes had discrepancies between the publication and the protocol (Table 2). Discrepancies between the protocol and publication were more common in unregistered trials (6 of 11 trials [55\%]) than registered trials (3 of 47 [6\%]) $(P<.001)$. Only 1 published article acknowledged the changes to primary outcomes.

Prospective registration was significantly associated with subsequent publication (68\% of registered trials vs $39 \%$ of unregistered trials; adjusted OR, 4.53 [95\% CI, 1.12-18.34]) (Table 1). Registered trials were also significantly more likely than unregistered trials to be subsequently published with the same primary outcomes as defined in the protocol (64\% of registered trials vs $25 \%$ of unregistered trials; adjusted OR, 5.79 [95\% CI, 1.42-23.65]).

Discussion | Clinical trials were often unregistered, unpublished, and discrepant in the reporting of primary outcomes across information sources. Limitations include the unclear generalizability beyond the Finnish jurisdiction and the limited sample size.

Although discrepancies are commonly found between registries and publications, ${ }^{3}$ which may reflect selective outcome reporting, the rationale is less clear for different primary outcomes appearing between the registry and protocol prior to results being known. Potential reasons for such discrepancies include clerical oversight or intentional suppression from disclosure. The original protocol and amendments should be made publicly available so that 
Table 2. Proportion of Trials With Discrepancies in Primary Outcomes When Comparing Protocols With Prospective Registry Records and Published Articles

\begin{tabular}{lll}
\hline & \multicolumn{2}{l}{$\begin{array}{l}\text { No. of Trials With Discrepancies } \\
\text { for } \geq 1 \text { Primary Outcome/ Total Trials (\%) }\end{array}$} \\
\cline { 2 - 3 } $\begin{array}{l}\text { Registry } \\
\text { vs Protocol }\end{array}$ & $\begin{array}{l}\text { Published Article } \\
\text { vs Protocol }\end{array}$ \\
\hline $\begin{array}{l}\text { Changed protocol-defined } \\
\text { primary outcome }\end{array}$ & $13 / 67(19)^{\mathrm{b}}$ & $5 / 55(9)^{\mathrm{e}}$ \\
$\begin{array}{l}\text { Reported as nonprimary } \\
\text { Omitted }\end{array}$ & $2 / 67(3)^{\mathrm{b}}$ & $5 / 55(9)^{\mathrm{e}}$ \\
\hline $\begin{array}{l}\text { New primary outcome } \\
\begin{array}{l}\text { Changed from nonprimary } \\
\text { to primary }\end{array}\end{array}$ & $12 / 67(18)^{\mathrm{b}}$ & $1 / 55(2)^{\mathrm{e}}$ \\
\hline $\begin{array}{l}\text { Not listed in protocol } \\
\text { Any discrepancy } \\
\text { in primary outcome }\end{array}$ & $3 / 63(5)^{\mathrm{c}}$ & $7 / 56(13)^{\mathrm{f}}$ \\
\hline
\end{tabular}

${ }^{a}$ Categories are not mutually exclusive; a trial could have more than 1 type of discrepancy for different primary outcomes.

${ }^{\mathrm{b}}$ Denominator represents registered trials that defined at least 1 primary outcome in the protocol.

c Denominator represents registered trials that defined at least 1 primary outcome in the registry.

${ }^{\mathrm{d}}$ Denominator represents registered trials that defined at least 1 primary outcome in either the protocol or registry.

${ }^{\mathrm{e}}$ Denominator represents published trials that defined at least 1 primary outcome in the protocol.

${ }^{\mathrm{f}}$ Denominator represents published trials that defined at least 1 primary outcome in the published article.

${ }^{\mathrm{g}}$ Denominator represents published trials that defined at least 1 primary outcome in either the protocol or published article. Five trials had only discrepancies that were favorable to the main intervention, 3 had only unfavorable discrepancies, and 1 had a neutral combination of both favorable and unfavorable discrepancies

editors, peer reviewers, and readers can identify any unacknowledged changes to protocol-defined outcomes in the registry or publication. ${ }^{4,5}$ The protocol should provide a complete description of the primary outcomes and other key elements of the study plans. ${ }^{6}$ Amendments should be transparently reported.

Prospective registration was associated with publication and publication without discrepancies in the primary outcomes. Journal editors, regulators, research ethics committees, funders, and sponsors should implement policies mandating prospective registration for all clinical trials. Only with accessible, complete information can interventions be adequately evaluated for patient care.

An-Wen Chan, MD, DPhil

Annukka Pello, MD

Jessica Kitchen, MSc

Anna Axentiev, BSc

Jorma I. Virtanen, DDS, DPhil

Annie Liu, MD

Elina Hemminki, MD, DrPH

Author Affiliations: Women's College Research Institute, University of Toronto, Toronto, Ontario, Canada (Chan, Kitchen, Axentiev, Liu); University of Helsinki, Helsinki, Finland (Pello); University of Oulu, Oulu, Finland (Virtanen); National Institute for Health and Welfare, Helsinki, Finland (Hemminki).

Accepted for Publication: August 11, 2017.
Corresponding Author: An-Wen Chan, MD, DPhil, Women's College Research Institute, 76 Grenville St, Room 6416, Toronto, ON, Canada M5S 1B2 (anwen.chan@utoronto.ca).

Published Online: September 11, 2017. doi:10.1001/jama.2017.13001

Author Contributions: Dr Chan had full access to all of the data in the study and takes responsibility for the integrity of the data and the accuracy of the data analysis.

Concept and design: Chan, Hemminki.

Acquisition, analysis, or interpretation of data: All authors.

Drafting of the manuscript: Chan, Hemminki.

Critical revision of the manuscript for important intellectual content: All authors. Statistical analysis: Chan.

Obtained funding: Chan, Hemminki.

Administrative, technical, or material support: Kitchen, Axentiev, Virtanen, Liu, Hemminki.

Supervision: Chan, Hemminki.

Conflict of Interest Disclosures: All authors have completed and submitted the ICMJE Form for Disclosure of Potential Conflicts of Interest and none were reported.

Funding/Support: This project was supported in part by grant MET 117434 from the Canadian Institutes of Health Research Dissemination Events and grant 28356 from the Academy of Finland.

Role of the Funder/Sponsor: The funders had no role in the design and conduct of the study; collection, management, analysis, and interpretation of the data; preparation, review, or approval of the manuscript; and decision to submit the manuscript for publication.

Meeting Presentation: This article was presented at the Peer Review Congress September 10-12, 2017; Chicago, Illinois.

1. Dwan K, Gamble C, Williamson PR, Kirkham JJ; Reporting Bias Group. Systematic review of the empirical evidence of study publication bias and outcome reporting bias-an updated review. PLoS One. 2013;8(7):e66844.

2. Chan A-W, Hróbjartsson A, Haahr MT, Gøtzsche PC, Altman DG. Empirical evidence for selective reporting of outcomes in randomized trials: comparison of protocols to published articles. JAMA. 2004;291(20):2457-2465.

3. Jones CW, Keil LG, Holland WC, Caughey MC, Platts-Mills TF. Comparison of registered and published outcomes in randomized controlled trials: a systematic review. BMC Med. 2015;13:282.

4. Zarin DA, Tse T, Williams RJ, Carr S. Trial reporting in ClinicalTrials.gov-the final rule. N Engl J Med. 2016;375(20):1998-2004.

5. Chan A-W, Song F, Vickers A, et al. Increasing value and reducing waste: addressing inaccessible research. Lancet. 2014;383(9913):257-266.

6. Chan A-W, Tetzlaff JM, Altman DG, et al. SPIRIT 2013 statement: defining standard protocol items for clinical trials. Ann Intern Med. 2013;158(3):200-207.

\section{COMMENT \& RESPONSE}

\section{Alendronate and Hip Fracture in Patients Using Glucocorticoids}

To the Editor Dr Axelsson and colleagues ${ }^{1}$ evaluated the association between alendronate use and risk of hip fracture among older adults taking prednisolone. Although the availability of a large population-based cohort is a major strength, their study design comparing prevalent alendronate users with nonusers raises several concerns.

First, treated patients were required to have at least 3 months of alendronate use and evidence of current use at the start of follow-up for outcomes. Therefore, alendronate users who experienced safety events early in the treatment course and discontinued treatment because of the adverse event would not have been eligible for inclusion in this study. This could have resulted in underestimation of safety events due to depletion of susceptible patients from the treatment group..$^{2,3}$

Second, the outcome assessment was not anchored to treatment start but to enrollment in the Senior Alert program 